\title{
Implementasi Budaya Sipakatau, Sipakalebbi, Sipakainge dalam Meningkatkan Hasil Belajar Matematika SMA
}

\author{
Andi Kaharuddin ${ }^{1 *}$, Nasrun Syahrir ${ }^{2}$, Trisniawati ${ }^{3}$ \\ ${ }^{1}$ Pendidikan Matematika, Universitas Lakidende Unaaha, Kendari, Indonesia \\ ${ }^{2}$ Pendidikan Matematika, Universitas Muhammadiyah Makassar, Makassar, Indonesia \\ ${ }^{3}$ Pendidikan Matematika, Universitas Sarjanawiyata Tamansiswa, Yogyakarta, Indonesia
}

Pengiriman: 05/02/2020; Diterima: 23/10/2020; Publikasi: 20/11/2020

DOI: 10.31629/kiprah.v8i2.1964

\begin{abstract}
Abstrak
Sipakatau, sipakalebbi dan sipakainge merupakan budaya moral Bugis di Sulawesi Selatan yang perlu dilestarikan di dalam pembelajaran. Tujuan penelitian ini untuk melihat peningkatan hasil belajar matematika siswa SMA dari implementasi budaya sipakatau, sipakalebbi, sipakainge. Penelitian ini termasuk metode penelitian tindakan kelas. Delapan puluh delapan siswa kelas IPA XI SMA Negeri 5 Makassar menjadi sampel penelitian. Instrumen yang digunakan dalam mengumpulkan data menggunakan instrumen observasi dan tes hasil belajar siswa. Hasil penelitian ini menunjukan bahwa: (1) Implementasi budaya sipakatau meningkatkan hasil belajar siswa sebanyak 87\%; (2) Implementasi budaya sipakalebbi meningkatkan hasil belajar siswa sebanyak 88\%; dan (3) Implementasi budaya sipakainge meningkatkan hasil belajar siswa sebanyak $85 \%$. Secara umum disimpulkan bahwa implementasi budaya sipakatau, sipakalebbi dan sipakainge meningkatkan hasil belajar siswa kelas IPA XI SMA Negeri 5 Makassar sebesar 86\%.
\end{abstract}

Kata kunci: pembelajaran matematika; sipakainge; sipakalebbi; sipakatau

\begin{abstract}
Sipakatau, sipakalebbi, and sipakainge are bugis moral cultures in South Sulawesi that need to be preserved in learning. The aim to see the improving in mathematics learning outcomes of high school students from the implementation of the culture of Sipakatau, Sipakalebbi, Sipakainge. This research was a class action research method. 88 students of class XI IPA of SMAN Negeri 3 Makassar became the research sample. The instrument used to collect data uses student learning outcomes tests. The results of this study indicated that as many: (1) the application of sipakainge culture increases student learning outcomes by $87 \%$. (2) the application of sipakalebbi culture increases student learning outcomes by $88 \%$. and (3) the application of sipakainge culture increases student learning outcomes by $85 \%$. In general, it is concluded that the implementation of sipakatau, sipakalebbi and sipakainge culture improves student learning outcomes of class XI IPA SMAN 5 Makassar by $86 \%$.
\end{abstract}

Keywords: mathematics learning; sipakainge; sipakalebbi; sipakatau

\section{PENDAHULUAN}

Matematika merupakan bidang ilmu yang hadir pada setiap aspek kehidupan manusia, misal bidang ekonomi, bidang sosial, bidang geografi, bidang fisika, dan lain-lain. Pernyataan tersebut mengartikan bahwa matematika merupakan induk dari semua bidang kehidupan. Oleh karena itu, sangat penting bagi manusia untuk belajar matematika.

Proses belajar mengajar telah dilaksanakan jauh sebelum Indonesia merdeka, 
hal ini terbukti dari banyaknya dokumentasi sejarah tentang pembelajaran pada masa penjajahan Belanda dan Jepang. Setelah Indonesia merdeka, pemerintah Indonesia mendirikan sekolah pertama dengan sebutan sekolah taman siswa. Sekolah inilah yang berkembang hingga sekarang. Beberapa kurikulum berubah seiring pergantian pemerintahan.

Pidato Menteri Pendidikan dan Kebudayaan menyampaikan dalam pidatonya bahwa sekolah merupakan lembaga pendidikan yang bertujuan untuk mencetak generasi emas berakhlak mulia, berkarakter, dan berprestasi menuju Indonesia maju. Penjelasan tersebut mengartikan bahwa siapa pun pemimpinnya tujuan cita cita nasional pendidikan Indonesia yaitu mencerdaskan kehidupan bangsa tetap terwujud.

Kurikulum 2013 membagi tujuan pendidikan menjadi beberapa aspek yaitu kognitif, afektif dan psikomotorik. Kaharuddin (2019) menjelaskan bahwa (1) aspek kognitif memberikan tujuan untuk meningkatkan pemahaman, pengetahuan, penerapan analisis, sintesis, dan evaluasi siswa; (2) aspek afektif memberikan tujuan untuk meningkatkan respons, moral, minat, dan karakter siswa; (3) aspek psikomotorik memberikan tujuan ke ranah keterampilan siswa.

Penelitian ini menyoroti aspek afektif siswa khususnya pada siswa SMA dalam pembelajaran matematika. Berdasarkan hasil survei, nilai hasil ulangan matematika siswa semester genap tahun ajaran 2018/2019 sangat rendah atau di bawah rata-rata dari kriteria ketuntasan minimum yang diterapkan sekolah. Berlanjut ke wawancara guru, ternyata pokok permasalahan utama ialah siswa tidak memerhatikan guru dalam menanggapi pembelajaran khususnya pembelajaran matematika. Generasi millennial sekarang ini lebih mengutamakan internet sehingga ketika diberikan soal, siswa tidak membuka catatan melainkan browsing di internet, meskipun hal tersebut dilarang oleh guru, tentunya hal tersebut kurang menghargai guru. Fakta selanjutnya kurangnya rasa hormat kepada guru yang lebih muda, sehingga guru matematika yang mengajar sering tidak didengarkan ketika ditegur di dalam proses belajar mengajar.

Fakta fakta di atas menjadi dasar sementara peneliti untuk memberikan solusi dari masalah yang terjadi disekolah khususnya sekolah SMAN 5 Makassar kelas IPA XI, karena akan berdampak kepada nilai hasil belajar siswa.

Pembelajaran matematika harus lebih diberdayakan dengan mendukung pengembangan kepribadian siswa dalam pembelajaran (Nahdi, 2017). Karakter yang baik akan membentuk kepribadian siswa yang baik (Setiawan \& Sulistiani, 2019). Olehnya itu, salah satu alternatif yang bisa dilakukan ialah dengan meningkatkan aspek afektif siswa yaitu moral yang baik siswa kepada guru sehingga nantinya siswa cenderung mendengar arahan dan penjelasan dari guru selama proses pembelajaran.

Etika adat di Indonesia timur memperlihatkan bahwa yang lebih muda menghormati yang lebih tua, baik dari tutur kata dan tingkah laku. Pernyataan singkat di atas sangat cocok diterapkan di dalam pembelajaran seperti masalah yang didapatkan peneliti saat ini.

Setelah ditelusuri ternyata etika adat ketimuran yang dimaksud seperti yang dikemukakan (Sari \& Razak, 2015; Sulo, 2018) ialah sipakatau berarti saling menghargai, saling menopang, saling mengayomi, saling menuntun, saling membagi, dan saling memberi yang dalam lingkup sekolah dapat diimplementasikan melalui sikap menghargai. Sipakalebbi berarti saling menghormati dalam lingkup sekolah bukan berarti harus takut kepada guru, tetapi sangat penting diterapkan kepada siswa bahwa dalam tata krama "yang muda menghormati yang tua sedangkan yang tua menyayangi yang muda". Sipakainge berarti saling mengingatkan siswa pada setiap awal pembelajaran akan norma-norma agama, adat istiadat, sopan santun, dan berbagai nilai karakter. Hal ini akan bermuara pada etika 
siswa dalam berbahasa, bersikap dan bertindak baik dalam kegiatan pembelajaran matematika maupun di lingkungan masyarakat. Pernyataan tersebut diperkuat oleh (Nawawi, 2011; Sahroni, 2017) bahwa pendidikan karakter sangat penting bagi generasi penerus dalam pembelajaran karena akan berdampak kepada proses pembelajaran.

Solusi tersebut sejalan dengan temuan (Cheriani, Mahmud, Tahmir, Manda, \& Dirawan, 2015) bahwa pendidikan karakter siswa akan meningkat dan menguat sejalan dengan pembelajaran matematika dan diterapkannya kearifan budaya lokal untuk mengimbangi teknologi digital. pendapat tersebut ditambahkan oleh (Prabowo \& Sidi, 2010) bahwa dengan menanamkan penguatan karakter kepada siswa sesungguhnya akan meningkatkan motivasi, apresiasi, kontribusi, sikap dan ketekunan dalam.

Berdasarkan uraian di atas, urgensi di dalam penelitian ini adalah implementasi budaya lokal sipakatau, sipakalebbi dan sipakainge terhadap peningkatan hasil belajar siswa

\section{METODE PENELITIAN}

Penelitian ini merupakan penelitian tindakan kelas. Subjek penelitian dalam penelitian ini 88 siswa kelas IPA XI SMA Negeri 5 Makassar. (Brenny Novriansyah, 2013; Kaharuddin \& Liasambu, 2019; Situmorang \& ., 2017) mengemukakan bahwa penelitian tindakan kelas memiliki prosedur penelitian dan tahapan yaitu yaitu perencanaan, tindakan, observasi dan refleksi yang dilaksanakan beberapa siklus sampai memenuhi indikator keberhasilan yaitu ditunjukkan adanya peningkatan hasil belajar siswa rata rata minimal $>70$ dari ketuntasan secara klasikal $\geq 85 \%$.

Instrumen yang digunakan untuk mengumpulkan data yaitu tes hasil belajar matematika dan lembar observasi aktivitas siswa di dalam pembelajaran dan lembar observasi keterlaksanaan pembelajaran.

Analisis data yang digunakan adalah analisis deskriptif.

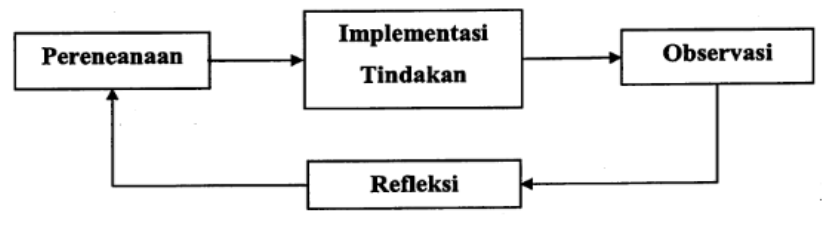

Gambar 1. Tahapan Penelitian

Sumber: Sanjaya (2010)

Pada tahapan perencanaan, peneliti merumuskan konsep pembelajaran $3 \mathrm{~S}$ ke dalam perangkat pembelajaran dan instrumen yang akan digunakan di dalam pembelajaran. Selanjutnya, tahapan implementasi peneliti melaksanakan pembelajaran sesuai dengan perangkat pembelajaran (RPP, bahan ajar, dan LKS) dan instrumen tes hasil belajar. Tahapan observasi peneliti dibantu oleh guru untuk melakukan observasi kepada siswa dalam proses pembelajaran dan observasi terhadap keterlaksanaan pembelajaran yang dilakukan oleh peneliti. Tahapan terakhir yaitu refleksi, peneliti melakukan diskusi dengan guru berdasarkan hasil belajar siswa apakah sudah memenuhi kriteria secara klasikal atau belum. Diskusi ini dilakukan untuk merancang pembelajaran siklus berikutnya.

\section{HASIL DAN PEMBAHASAN}

Berikut disajikan hasil penelitian dan pembahasan per siklus.

\section{Siklus I}

Siklus I diperoleh nilai hasil belajar dari penerapan konsep belajar dengan budaya $3 \mathrm{~S}$ yang dapat dilihat pada Gambar 2:

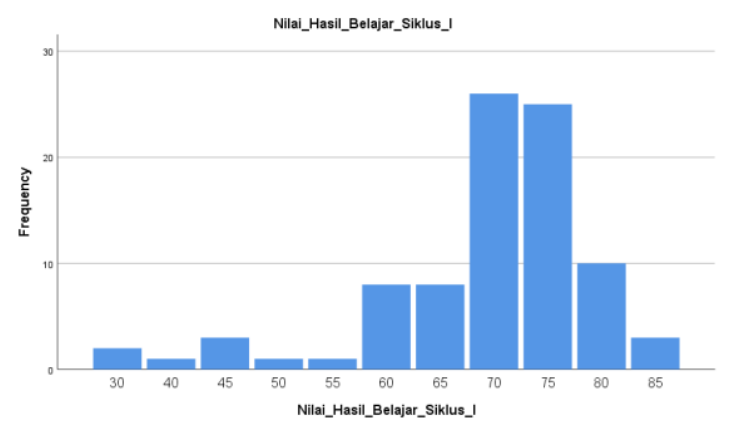

Gambar 2. Nilai Hasil Belajar Siklus I

Dari Gambar 2 terlihat bahwa sebaran data nilai hasil belajar siswa bervariasi dengan nilai terendah 30 dan nilai tertinggi 85. Variasi 
nilai ini terjadi dari proses pembelajaran yang belum maksimal dari penerapan konsep $3 \mathrm{~S}$ dalam pembelajaran. Secara klasikal perolehan nilai hasil belajar siswa pada siklus I sebesar $43 \%$ dengan nilai rata-rata 69.

Siklus I dari implementasi konsep belajar dengan budaya sipakatau telah meningkatkan nilai hasil belajar siswa dari nilai ulangan harian matematika sebesar $31 \%$ siswa dari 88 siswa. Implementasi konsep belajar dengan budaya sipakalebbi telah meningkatkan nilai hasil belajar siswa dari nilai ulangan harian matematika sebanyak $33 \%$ siswa 37 siswa dari 88 siswa. Implementasi konsep belajar dengan budaya sipakainge telah meningkatkan nilai hasil belajar siswa dari nilai ulangan harian matematika sebanyak $40 \%$ siswa dari 88 siswa Tabel 1. Skor Observasi Aktivitas Siswa

\begin{tabular}{|c|c|}
\hline Skor & Kategori \\
\hline 3,19 & Cenderung Positif \\
\hline
\end{tabular}

Tabel 1 mengindikasikan bahwa aktivitas siswa selama penerapan pembelajaran dengan konsep budaya $3 \mathrm{~S}$ cenderung positif. Hal ini terlihat dari hasil observasi dalam proses pembelajaran diperoleh informasi bahwa budaya adat bugis sipakatau siswa telah saling menghargai, saling menuntun, dan saling membagi dalam proses pembelajaran. Hal ini terlihat dari kerja sama secara berkelompok dan tidak membeda-bedakan. Pada sipakalebbi, siswa telah saling menghormati dan menghargai. Hal ini terlihat pada saat siswa bekerja secara berkelompok menghargai pendapat ketua dan anggota kelompok. Pada sipakainge, siswa telah saling mengingatkan. Hal ini terlihat dari aktivitas siswa menuntun teman kelompoknya jika keliru serta berdiskusi dalam menyelesaikan suatu permasalahan dalam soal, mengambil keputusan sesuai dengan hasil diskusi kelompok.

Tabel 2. Skor Observasi Ketelaksanaan Pembelajaran

\begin{tabular}{|c|c|}
\hline Skor & Kategori \\
\hline 3,26 & $\begin{array}{r}\text { Terlaksanan } \\
\text { dengan Baik }\end{array}$ \\
\hline
\end{tabular}

Tabel 2 mengartikan bahwa penerapan pembelajaran budaya $3 \mathrm{~S}$ dalam pembelajaran matematika terlaksana dengan baik, artinya ada beberapa aspek dari indikator pembelajaran yang belum memenuhi kriteria sangat baik sehingga skor keterlaksanaan pembelajaran 3,26.

Tahapan 3S yang belum terlaksana dengan sangat baik ialah tahapan sipakainge. Pada tahap ini, siswa belum mampu mengingatkan temannya yang keliru dalam mengerjakan soal yang diberikan oleh guru, sedangkan pada tahapan sipakalebbi dan sipakainge telah terlaksana dengan sangat baik.

Secara garis besar dapat dilihat bahwa pada siklus I dari penerapan budaya $3 \mathrm{~S}$, pembelajaran matematika telah meningkatkan nilai hasil belajar dari nilai ulangan harian matematika meskipun belum mencapai nilai kriteria ketuntasan minimal dan ketuntasan secara klasikal. Namun, untuk skor aktivitas dan keterlaksanaan pembelajaran cenderung positif dan telah terlaksana dengan baik, sehingga secara garis besar implementasi pembelajaran konsep budaya $3 \mathrm{~S}$ telah meningkatkan nilai hasil belajar siswa kelas IPA XI SMA Negeri 5 Makassar.

Meskipun begitu, nilai hasil belajar pada siklus I telah meningkat dari nilai ulangan harian matematika siswa. Namun, nilai belum memenuhi kategori yang ditentukan di dalam penelitian, sehingga dilanjutkan ke siklus II.

\section{Siklus II}

Pada siklus II diperoleh nilai hasil belajar dari penerapan konsep belajar dengan budaya $3 \mathrm{~S}$ yang dapat dilihat pada Gambar 3 :

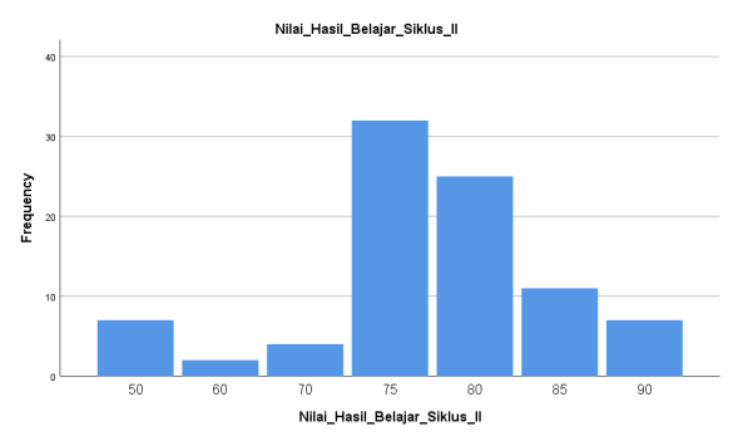

Gambar 3. Nilai Hasil Belajar Siklus II 
Dari Gambar 3 terlihat bahwa sebaran data nilai hasil belajar siswa bervariasi, tetapi rentang nilai dari variasi nilai siswa cenderung homogen. Ini dapat dilihat dari perolehan nilai tertinggi yaitu 90 dengan rata rata 77 . Adapun nilai siswa yang rendah dengan skor 50 telah meningkat dari 10 siswa dengan nilai di bawah 50 menjadi 3 siswa pada siklus I ke siklus II. Secara klasikal perolehan nilai hasil belajar siswa pada siklus II sebesar $86 \%$ dengan nilai rata-rata 77.

Siklus II dari implementasi konsep belajar dengan budaya sipakatau telah meningkatkan hasil belajar siswa sebesar sebanyak $87 \%$ siswa dari 88 siswa. Implementasi konsep belajar dengan budaya sipakalebbi telah meningkatkan hasil belajar sebanyak $88 \%$ siswa dari 88 siswa. Implementasi konsep belajar dengan budaya sipakainge telah meningkatkan hasil belajar siswa sebanyak $86 \%$ siswa dari 88 siswa. Dikarenakan indikator keberhasilan telah tercapai pada siklus II maka proses PTK sudah memenuhi.

Tabel. 3 Skor Observasi Aktivitas Siswa

\begin{tabular}{|c|c|}
\hline Skor & Kategori \\
\hline 3,70 & Positif \\
\hline
\end{tabular}

Tabel 3 mengindikasikan bahwa aktivitas siswa selama penerapan pembelajaran dengan konsep budaya $3 \mathrm{~S}$ positif. Hal ini terlihat dari hasil observasi dalam proses pembelajaran diperoleh bahwa budaya adat bugis sipakatau siswa telah saling menghargai, saling menopang, saling mengayomi, saling menuntun, saling membagi, dan saling memberi dalam proses pembelajaran. Ini terlihat dari kerja sama dan kekompakkan secara berkelompok dan tidak membedabedakan ras, suku dan agama. Pada sipakalebbi, siswa telah saling menghormati, hal ini terlihat pada saat siswa bekerja secara berkelompok menghargai pendapat teman di sampingnya, menambahkan dan meluruskan pendapat temannya yang keliru dan tidak menyinggung. Pada sipakainge, siswa telah saling mengingatkan dan memberikan pemahaman kepada teman kelompok jika yang dilakukan keliru dan memberikan solusi secara halus serta berdiskusi dalam menyelesaikan suatu permasalahan dalam soal, mengambil keputusan sesuai dengan hasil diskusi kelompok.

Tabel 4. Skor Observasi Ketelaksanaan Pembelajaran

\begin{tabular}{|c|c|}
\hline Skor & Kategori \\
\hline 3,73 & $\begin{array}{c}\text { Terlaksana } \\
\text { dengan Sangat Baik }\end{array}$ \\
\hline
\end{tabular}

Tabel 4 mengartikan bahwa penerapan pembelajaran budaya $3 \mathrm{~S}$ dalam pembelajaran matematika terlaksana dengan sangat baik. Artinya seluruh aspek dari indikator pembelajaran yang telah memenuhi kriteria sangat baik sehingga skor keterlaksanaan pembelajaran 3,73.

Tahapan 3S terlaksana dengan sangat baik ini dilihat dari siklus I sebelumnya. Pada tahapan sipakainge siswa mampu mengingatkan temannya yang keliru dalam mengerjakan soal yang diberikan oleh guru terbukti dari nilai hasil belajar siswa yang homogen. Hal ini didukung berdasarkan hasil observasi ternyata selama proses pembelajaran siswa menjadi tutor sebaya dan saling berbagi wawasan agar siswa lain paham dengan penyelesaian dari soal yang diberikan oleh guru.

Secara garis besar dapat dilihat bahwa pada siklus II dari penerapan budaya 3S dalam pembelajaran matematika telah meningkatkan nilai hasil belajar dari nilai ulangan harian matematika dan telah mencapai nilai kriteria ketuntasan minimal serta ketuntasan secara klasikal, skor aktivitas dan keterlaksanaan pembelajaran positif, dan telah terlaksana dengan sangat baik. Jadi, secara garis besar implementasi pembelajaran konsep budaya $3 \mathrm{~S}$ telah meningkatkan nilai hasil belajar siswa kelas IPA XI SMA Negeri 5 Makassar.

Dari hasil dan pembahasan di atas tentang siklus I dan siklus II diperoleh fakta bahwa implementasi budaya Bugis (sipakatau, sipakalebbi, dan sipakainge) meningkatkan nilai hasil belajar siswa. Ini terlihat dari peningkatan nilai hasil belajar dari siklus I ke siklus II dan skor perolehan observasi dari 
penerapan budaya $3 \mathrm{~S}$ dalam pembelajaran matematika. Sejalan dengan hasil penelitian (Akib, 2016) tentang karakteristik bugis dalam pembelajaran matematika memberikan hasil bahwa budaya bugis memiliki peranan penting dalam meningkatkan hasil belajar siswa.

Nurcaya (2018) mengemukakan adaptasi nilai kearifan lokal akan menjadi bekal siswa untuk mengembangkan aspek intelektual dan sosial, ini terlihat dari hasil penelitian pada aspek sipakainge dimana siswa saling membantu dan mengingatkan dalam pembelajaran. Alimin \& Widjajanti (2019) mengemukakan bahwa dengan penanaman budaya bugis membantu siswa mengurangi kecemasan dalam pembelajaran. Ini terlihat dari hasil penelitian pada aspek sipakalebbi yaitu saling menghargai pendapat temannya ketika keliru dalam menjawab soal. Cheriani (2019) juga mengemukakan bahwa implementasi budaya bugis meningkatkan kemampuan pemecahan masalah siswa. Ini terlihat dari hasil penelitian pada aspek sipakatau, siswa saling menuntun dalam pembelajaran sehingga secara madiri siswa mampu menjawab soal yang diberikan guru.

Uraian tersebut terlihat bahwa penanaman karakter dari budaya bugis sipakatau, sipakalebbi, dan sipakainge mampu membantu siswa dalam pembelajaran matematika. Temuan tersebut mendukung pendapat (Syarif, Sumarmi, \& Astina, 2016) bahwa salah satu strategi menghadapi era masyarakat ekonomi asean yaitu dengan mengintegrasikan buadaya lokal bugis dalam proses pembelajaran. Maka dari itu, berdasarkan penelitian yang relevan dan hasil yang diperoleh di dalam penelitian ini dapat diinterpretasikan bahwa budaya sipakatau, sipakalebbi, dan sipakainge dapat meningkatkan hasil belajar siswa kelas IPA XI SMA Negeri 5 Makassar.

Hasil dalam penelitian ini dapat menjadi modal dasar guru untuk meningkatkan nilai hasil belajar siswa terutama dalam pembelajaran matematika. Hal ini disebabkan dalam prosesnya telah dijabarkan bagaimana membentuk moral dan karakter yang baik, karena pada dasarnya semua siswa memiliki rasa ingin tahu yang tinggi.

\section{KESIMPULAN}

Berdasarkan rumusan masalah yang telah diuraikan diperoleh hasil bahwa dengan implementasi nilai budaya sipakatau, sipakalebbi, dan sipakainge dapat meningkatkan hasil belajar matematika siswa SMA dilihat dari indikator keberhasilan siklus I dan siklus II. Implementasi budaya sipakatau meningkatkan hasil belajar siswa sebanyak $87 \%$, implementasi budaya sipakalebbi meningkatkan hasil belajar siswa sebanyak $88 \%$, dan implementasi budaya sipakainge meningkatkan hasil belajar siswa sebanyak $85 \%$. Secara umum disimpulkan bahwa implementasi budaya sipakatau, sipakalebbi dan sipakainge meningkatkan hasil belajar siswa kelas IPA XI SMAN 5 Makassar sebesar $86 \%$. Oleh karena itu, diharapkan kepada guru dalam proses pembelajaran lebih mengedepankan pembentukan moral sebab moral yang baik tercipta dari didikan yang baik.

\section{REFERENSI}

Akib, I. (2016). The description of relationship between mathematics charasteristic and Bugis culture values. Global Journal of Pure and Applied Mathematics, 12(4), 2765-2776.

Alimin, B. R., \& Widjajanti, D. B. (2019). Managing Students Mathematical Anxiety trough a Bugis-Makassar Culture-Based Learning Model. Journal of Physics: Conference Series, 1320(1), 1-7. $\quad$ https://doi.org/10.1088/17426596/1320/1/012047

Brenny Novriansyah, M. P. (2013). Penelitian Tindakan Kelas ( PTK ) Penerapan Metode Make A MAtch Berbasis Pancingan Kata Sebagai Upaya Meningkatkan Kemampuan Menulis Bahasa Arab Siswa Kelas XII IPA 3 MAN 1 Model Bengkulu.

Cheriani. (2019). The Influence of the Implementation of the Sipatuo Sipatokkong Bugis Culture Integrated with the Problem Based Learning Model. The 2nd International Conference on Natural \& Social Sciences (ICONSS 
2019), (September), 180-185.

Cheriani, Mahmud, A., Tahmir, S., Manda, D., \& Dirawan, G. D. (2015). Problem-based learning-buginese cultural knowledge model-case study: Teaching mathematics at junior high school. International Education Studies, 8(4), 104-110. https://doi.org/10.5539/ies.v8n4p104

Kaharuddin, A. (2019). Effect of Problem Based Learning Model on Mathematical Learning Outcomes of 6th Grade Students of Elementary School Accredited B in Kendari City. International Journal of Trends in Mathematics Education Research, 1(2), 43-46.

https://doi.org/10.33122/ijtmer.v1i2.14

Kaharuddin, A., \& Liasambu, L. (2019). Penerapan Model STAD dalam Meningkatkan Hasil Belajar dan. Jurnal Pendidikan Matematika Raflesia, 04(02), 29-37.

https://doi.org/10.33449/jpmr.v4i2.9750

Nahdi, D. S. (2017). Membentuk Karakter Siswa Dengan Menanamkan Nilai-Nilai Matematika. NATURALISTIC: Jurnal Kajian Penelitian Pendidikan Dan Pembelajaran, 2(1), 1-7. https://doi.org/10.35568/naturalistic.v2i1. 29

Nawawi, A. (2011). Pentingnya Pendidikan Nilai Moral Bagi Generasi Penerus. Jurnal Kependidikan: Insania, 16(2), 119-133. Retrieved from c:/Users/asus/Downloads/1582-Article Text-3012-1-10-20180527.pdf

Nurcaya. (2018). Learning for Character Strength Through Local Wisdom ( Bugis People Story ). Journal of Innovative Studies on Character and Education, 2(2), 340-349. Retrieved from file:///Users/seniwati/Downloads/44-881-SM.pdf

Prabowo, A., \& Sidi, P. (2010). Memahat karakter melalui pembelajaran matematika. Proceeding of the 4th International Conference on Teacher Education; Join Conference UPI \& UPSI, (November), 165-177.

Sahroni, D. (2017). PENTINGNYA PENDIDIKAN KARAKTER DALAM PEMBELAJARAN. Prosiding Seminar Bimbingan Dan Konseling, 115-124.

Sanjaya, D. H. W. (2016). Penelitian tindakan kelas. Prenada Media.
Sari, F., \& Razak, H. (2015). Kuasa Wacana Kebudayaan Jurnal Politik Profetik Volume 5 Nomor 1 Tahun 2015. 5, 1635.

Setiawan, A., \& Sulistiani, I. R. (2019). Pendidikan Nilai, Budaya Dan Karakter Dalam Pembelajaran Matematika Dasar Pada Sd/Mi. Elementeris : Jurnal Ilmiah Pendidikan Dasar Islam, 1(1), 41. https://doi.org/10.33474/elementeris.v1i1 .2767

Situmorang, M., \& . L. (2017). Upaya Meningkatkan Hasil Belajar Siswa Pada Mata Pelajaran Menggambar Teknik Melalui Model Pembelajaran Kooperatif Tipe Team Quiz Pada Siswa Kelas X Program Keahlian Teknik Mesin Produksi Smk Negeri 2 Tanjungbalai T.a 2016/2017. Jurnal Pendidikan Teknologi Dan Kejuruan, 19(1), 19-25. https://doi.org/10.24114/jptk.v19i1.7151

Sulo, M. (2018). The Meaning of Sipakatau Sipakalebbi Sipakainge in Wajo ( A Semantical Analysis ). 19(2), 34-40.

Syarif, E., Sumarmi, S., \& Astina, I. K. (2016). Integrasi Nilai Budaya Etnis Bugis Makassar Dalam Proses Pembelajaran Sebagai Salah Satu Strategi Menghadapi Era Masyarakat Ekonomi Asean (MEA). Jurnal Teori Dan Praksis Pembelajaran IPS, $\quad 1(1), \quad 13-21$. https://doi.org/10.17977/um022v1i12016 p013 